\title{
PENGARUH TEMPERATUR HIDROLISIS ASAM DAN WAKTU FERMENTASI TERHADAP KADAR BIOETANOL TETES TEBU
}

\author{
Mugiyono Saputra1, Dwi Irawan², Mafruddin³ \\ Jurusan Teknik Mesin, Fakultas Teknik, Universitas Muhammadiyah Metro \\ Jl. Ki Hajar Dewantara 15 A Metro, Lampung, Indonesia \\ Email: andasaja74@gmail.com¹,dwi_irawan@yahoo.co.id², mafruddin.mawon@yahoo.com³
}

\begin{abstract}
Abstrak
Pada masa sekarang bahan bakar menjadi kebutuhan pokok masyarakat dan pemakaiannya cenderung meningkat setiap tahunnya sedangkan sumber bahan bakar minyak bumi yang dipakai saat ini semakin menipis. Oleh karena itu perlu bahan bakar alternatif yang dapat digunakan sebagai pengganti minyak bumi. Bioetanol merupakan salah satu bahan bakar alternatif yang dapat digunakan sebagai pengganti minyak bumi. Bioetanol dapat dihasilkan dari karbohidrat. Karbohidrat yang digunakan pada penelitian ini berasal dari tetes tebu. Adapun tujuan dari penelitian ini adalah untuk mengetahui pengaruh temperatur hidrolisis asam dan waktu fermentasi terhadap kadar bioetanol yang dihasilkan. Metode penelitian yang dilakukan yaitu eksperimen nyata dengan memveriasikan temperatur hidrolisis asam yaitu $60^{\circ}$ $\mathrm{C}, 70^{\circ} \mathrm{C}, 80^{\circ} \mathrm{C}$ dan waktu fermentasi yaitu 5, 7, 9 hari. Dari hasil penelitian didapatkan bahwa temperatur hidrolisis asam dan waktu fermentasi berpengaruh terhadap kadar bioetanol. Kadar bioetanol yang paling tinggi adalah hidrolisis asam dengan suhu $80^{\circ} \mathrm{C}$ dengan kadar $58 \%$ dan kadar bioetnol paling rendah terdapat pada hidrolisis asam dengan suhu $60^{\circ} \mathrm{C}$ dengan kadar $22 \%$. Kadar bioetanol yang paling tinggi terdapat pada fermentasi 7 hari memperoleh kadar sebesar $58 \%$.
\end{abstract}

Kata Kunci: Tetes Tebu, Hidrolisis Asam, Fermentasi, Bioetanol.

\section{PENDAHULUAN}

Pada masa sekarang kecenderungan pemakaian bahan bakar sangat tinggi sedangkan sumber bahan bakar yang berasal dari fosil saat ini semakin menipis. Oleh karena itu, perlu adanya bahan alternatif yang dapat digunakan sebagai pengganti bahan bakar yang berasal dari fosil seperti minyak bumi.

Bioetanol merupakan salah satu jenis alkohol yang dapat dibuat dengan fermentasi karbohidrat atau reaksi kimia gas alam yang dapat diproduksi dari bahan alami terutama dari beberapa tumbuhan yang mengandung karbohidrat tinggi [1]. Tumbuhan yang sering digunakan untuk menghasilkan bioetanol salah satunya tetes tebu yang merupakan produk dari industri gula, singkong, dan kelompok pati-patian lainnya. Bahan-bahan baku tersebut kemudian difermentasikan dengan bantuan mikrorganisme Saccharomyces Cereviseae dan mikroba penghasil bioetanol yang berperan sebagai substrat untuk pertumbuhan mikroba dari proses fermentasi tersebut dihasilkan bioetanol.

Tetes tebu (molase) adalah salah satu hasil samping pabrik gula tebu yang masih mempunyai nilai ekonomi yang cukup disebabkan kandungan gulanya yang tinggi sekitar 52\% [2]. Dimana molase tersebut dapat dimanfaatkan untuk memproduksi bioetanol melalui proses fermentasi. Proses fermentasi merupakan salah satu faktor yang berpengaruh terhadap produksi bioetanol [3].

Untuk menghasilkan bioetanol diperlukan teknik pemisahan yang memisahkan antara cairan dan padatan digunakan teknik penyaringan (filtrasi). Untuk memisahkan bioetanol dari 
komponen cair digunakan teknik destilasi (penyulingan) dengan mamanfaatkan perbedaan titik uap antara bioetanol dan komponen-komponen cair lainnya.

Selain fermentasi faktor lain yang mempegaruhi hasil dari produsi bioetanol yaitu hidrolisis asam [4]. Hidrolisis asam merupakan proses pemutusan ikatan antar glukosa menggunakan air dengan bantuan katalis dan membutuhkan panas. Katalis yang digunakan dapat berupa katalis asam, basa atau enzim. Glukosa yang diperoleh melalui hidrolisis tadi kemudian dapat difermentasi menjadi suatu produk yaitu bioetanol.

Tujuan penelitian ini adalah untuk mengetahui pengaruh temperatur hidrolisis asam dan waktu fermentasi terhadap kadar bioetanol tetes tebu.

\section{TINJAUAN PUSTAKA}

Penelitian yang dilakukan oleh Retno dan Wasir dengan judul "pembuatan bioetanol dari kulit pisang" yang menyimpulkan bahwa semakin lama fermentasi kadar bioetanol yang dihasilkan akan semakin tinggi sampai waktu tertentu dan semakin banyak ragi yang ditambahkan menyebabkan kadar bioetanol yang dihasilkan semakin rendah [3].

Penelitian yang dilakukan oleh Purba dan Togu dengan judul "pengaruh lama fermentasi terhadap kadar bioetanol dari biji alpukat (Peersea Americana Mill) yang menyimpulkan bahwa kadar bioetanol bertambah seiring dengan bertambahnya lama fermentasi namun biji alpukat memiliki waktu optimum dalam pembuatan bioetanol, yaitu 96 jam [4].

Asngad dan suparti menyimpulkan bahwa tinggi rendahnya kadar alkohol setiap gramnya dipengaruhi oleh banyak sedikitnya kandungan karbohidrat. Hal ini menunjukan bahwa kadar karbohidrat yang lebih tinggi mempengaruhi kadar alkohol yang dihasilkan dalam proses fermentasi karbohidrat [5]. Sedangkan dalam penelitian Utami menunjukan, semakin lama waktu fermentasi maka semakin tinggi pula kadar alkohol yang dihasilkan dan semakin banyak dosis ragi yang diberikan maka kadar alkohol yang dihasilkan juga semakin tinggi [6].

Bioetanol merupakan jenis alkohol yang dapat dibuat dengan fermentasi karbohidrat atau reaksi kimia gas alam. Terdapat beberapa tumbuhan yang mengandung karbohidrat tinggi yang serig kita jumpai berupa jagung, sorgum, atau singkong yang biasanya digunakan untuk menghasilkan bioetanol [1]. Bioetanol merupakan cairan hasil proses fermentasi gula dari sumber karbohidrat (pati) menggunakan bantuan organisme [3]. Bioetanol merupakan bahan bakar dari tumbuhan yang memiliki sifat menyerupai minyak premium. Bahan baku pembuatan bioetanol dapat dibagi menjadi tiga kelompok, yaitu bahan sukrosa, bahan berpati, dan nitrogen, sehingga digunakan sebagai subtrat oleh mikroba untuk menghasilkan berbagai macam produk asam organik, seperti asam sitrat, asam asetat, asam glukonik, asam glutamat dan asam amino lysin [4].

Tetes tebu berupa cairan kental dan diperoleh dari tahap pemisahan kristal gula. Tetes tebu tidak dapat dibentuk lagi menjadi sukrosa namun masih mengadung gula dengan kadar tinggi 50-60\%, asam amino, dan mineral. Tetes tebu masih mengandung kadar gula yang cukup untuk dapat menghasilkan bioetanol dengan proses fermentasi, biasanya $\mathrm{pH}$ tetes tebu berkisar antara 5,5-6,5. Kandungan glukosa yang tinggi pada tetes tebu ini dapat mempermudah pada proses fermentasinya nanti [2].

Proses pembuatan bioetanol dari tetes tebu meliputi beberapa proses yaitu Hidrolisis Asam, Fermentasi dan Destilasi.

Hidrolisis merupakan proses antara reaktan dengan air agar suatu senyawa pecah atau terurai. Reaksi ini sering dianggap sebagai reaksi orde satu, karena air yang digunakan berlebih sehingga perubahan reaktan dapat diabaikan. Reaksi hidrolisa berlangsung sangat lambat sehingga perlu ditambah katalisatoir untuk mempercepat reaksi. Katalisator yang dipakai adalah zat 
asam. Hidrolisis asam dapat digunakan untuk memecah selulosa dan pati menjadi glukosa namun reaksi tersebut sangatlah lambat sehingga ditambahkan asam sulfat $\left(\mathrm{H}_{2} \mathrm{SO}_{4}\right)$ asam yang digunakan sebagai katalisator yang berfungsi untuk mempercepat reaksi. Asam sulfat biasanya digunakan pada bahan terlarut dengan konsentrasi asam 5-20\% dari setiap 1 liter bahan dengan suhu $80^{\circ} \mathrm{C}-120^{\circ} \mathrm{C}$ dengan waktu 30 sampai 240 menit [7]. Hidrolisa asam diperngaruhi oleh beberapa hal seperti ukuran bahan, konsentrasi asam, suhu, waktu, dan ratio bahan dan pengadukan [6].

Fermentasi adalah reaksi biokatalis digunakan untuk mengkonversi bahan baku susbtrat oleh enzim dari mikroba menjadi produk baru [8]. Mikroba terdiri atas bakteri, khamir (yeast) dan jamur (mold). Dalam suatu proses fermentasi bahan pangan seperti natrium klorida bermanfaat untuk membatasi pertumbuhan organisme pembusukan atau pertumbuhan sebagian organisme yang lain. Suatu fermentasi yang busuk biasaanya adalah fermentasi yang mengalami kontaminasi, sedangkan fermentasi yang normal adalah perubahan karbohidrat menjadi alkohol. Dalam pengertian yang luas, fermentasi adalah proses pemecahan gula-gula sederhana (glukosa dan fruktosa) menjadi bioetanol dan $\mathrm{CO}_{2}$ dengan melibatkan enzim yang dihasilkan pada ragi agar dapat bekerja pada suhu optimum. Proses fermentasi tergantung pada banyak sedikitnya penambahan khamir dalam bahan. Semakin banyak jumlah ragi yang diberikan berarti semakin banyak jumlah khamir yang terlibat, sehingga kadar alkohol meningkat [5].

Destilasi (peyulingan) merupakan proses untuk mendapatkan zat cair tidak murni kemudian diuapkan yang terbentuk diembunkan hingga diperoleh zat cair yang murni. Destilasi sendiri adalah salah satu metode pemisahan suatu komponen berdasarkan perbedaan titik didih. Dalam proses destilasi, pada suhu $80^{\circ} \mathrm{C}$ bioetanol akan menguap terlebih dahulu ketimbang air yang memiliki titik didih $100^{\circ} \mathrm{C}$, pada dasarnya zat yang memiliki titik didih lebih rendah akan menguap terlebih dahulu dibandingkan dengan zat yang memiliki titik didih yang lebih tinggi. Alat yang digunakan untuk memisahkan alkohol dengan cairan lainnya disebut dengan destilator.

\section{METODE PENELITIAN}

Penelitian dilakukan di kampus 2 Universitas Muhammadiyah Metro. Penelitian ini dilakukan dengan metode eksperimen nyata (true experimental research) dengan menvariasikan temperatur hidrolisis asam dan lama waktu fermentasi. Metode eksperimen meliputi tahap persiapan, pembuatan bioetanol, sampai dengan mengujian.

Langkah penelitian meliputi:

1. Studi pustaka

2. Pembuatan bioetanol

3. Pengujian kadar bioetanol

4. Analisis hasil eksperimen

Variabel yang digunakan dalam penelitian ini meliputi :

1. Variasi tempertur hidrolisis asam yang digunakan adalah $60^{\circ} \mathrm{C}, 70^{\circ} \mathrm{C}$, dan $80^{\circ} \mathrm{C}$.

2. Variasi lama waktu fermentasi yaitu 5 hari, 7 hari, dan 9 hari.

Bahan digunakan dalam penelitian yaitu:

1. Tetes tebu (molase)

2. Air

3. Ragi

4. Asam sulfat $\left(\mathrm{H}_{2} \mathrm{SO}_{4}\right)$.

Sedangkan alat yang digunakan dalam penelitian yaitu:

1. Termokopel

5. Gelas ukur

2. Termokontrol

6. Bak fermentasi

3. Ketel perebusan

7. Kompor listrik

4. Alat destilasi

8. Wadah penampung.

Prosedur pembuatan bioetanol yaitu:

1. Menyiapkan alat dan bahan

2. Mencampurkan tetes tebu dan air

3. Memanaskan campuran tetes tebu dan air serta menambahkan asam sulfat $\left(\mathrm{H}_{2} \mathrm{SO}_{4}\right)$

4. Menambahkan ragi pada campuran tetes tebu dan air serta asam sulfat.

5. Proses fermentasi

6. Destilasi 


\section{HASIL DAN PEMBAHASAN}

Dari hasil penelitian yang telah dilakukan diperoleh bioetanol seperti pada gambar berikut:

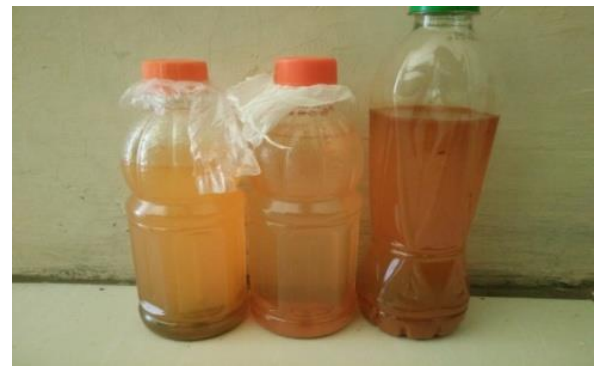

Gambar 1. Bioetanol

Dari hasil pengujian dipeoleh grafik hubungan antara temperatur hidrolisis asam dan waktu fermentasi terhadap hasil destilasi

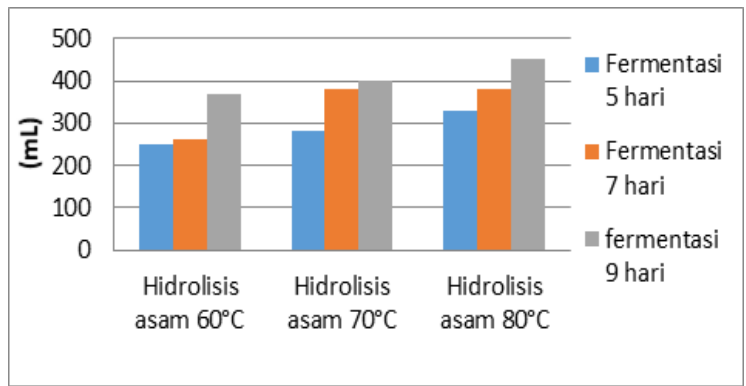

Gambar 2. Grafik Hubungan Temperatur Hidrolisis Asam Dan Waktu Fermentasi

Terhadap Hasil Destilasi

Dari Gambar 2. Grafik hubungan temperatur hidrolisis asam dan waktu fermentasi terhadap hasil destilasi diketahui bahwa semakin tinggi temperatur hidrolisis asam dan semakin lama waktu fermentasi menghasilkan bioetanol yang semakin besar. Pada hidrolisis asam $60^{\circ} \mathrm{C}$ dengan fermentasi 5, 7, dan 9 hari diperoleh hasil bioetanol sebesar $250 \mathrm{ml}, 260 \mathrm{ml}$, dan 370 $\mathrm{ml}$. Sementara untuk hidrolisis asam $70^{\circ} \mathrm{C}$ dengan waktu fermentasi yang sama yaitu 5 , 7, dan 9 hari diperoleh hasil bioetanol 280 $\mathrm{ml}, 380 \mathrm{ml}$ dan $400 \mathrm{ml}$. Dan pada hidrolisis asam $80^{\circ} \mathrm{C}$ dengan waktu fermentasi 5,7 , dan 9 hari menghasilkan bioetnol sebesar $330 \mathrm{ml}, 380 \mathrm{ml}$ dan $450 \mathrm{ml}$.

Grafik hubungan temperatur hidrolisis asam terhadap waktu destilasi yaitu sebagai berikut.

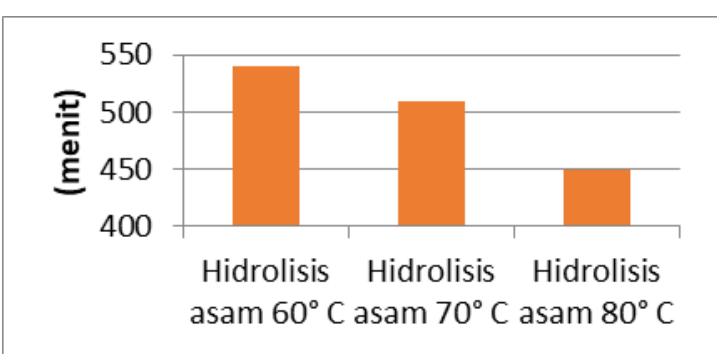

Gambar 3. Grafik Hubungan temperatur hidrolisis asam terhadap waktu destilasi

Dari Gambar 3. Grafik Hubungan temperatur hidrolisis asam terhadap waktu destilasi dapat diketahui perbedaan waktu yang dibutuhkan saat proses destilasi. Pada saat bahan dihidrolisis asam dengan suhu $60^{\circ} \mathrm{C}$ membutuhkan waktu yang cukup lama yaitu 540 menit untuk proses destilasi, sementara berbeda dengan bahan yang dihidrolisis asam pada suhu $70^{\circ} \mathrm{C}$ membutuhkan waktu 510 menit untuk satu kali proses destilasi dan untuk hidrolisis asam $80^{\circ} \mathrm{C}$ membutuhkan waktu 450 menit untuk proses destilasi.

Grafik hubungan temperatur hidrolisis asam dan waktu fermentasi terhadap kadar bioetanol yaitu sebagai berikut.

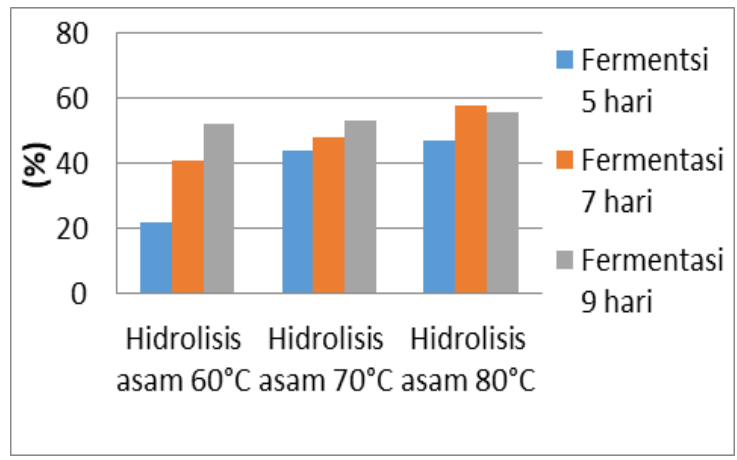

Gambar 4. Grafik Hubungan Temperatur

Hidrolisis Asam Dan Waktu Fermentasi

Terhadap Kadar Bioetanol

Dari Gambar 4. Grafik Hubungan Temperatur Hidrolisis Asam Dan Waktu Fermentasi Terhadap Kadar Bioetanol dapat diketahui bahwa temperatur hidrolisis asam dan waktu fermentasi berpengaruh terhadap kadar bioetanol yang dihasilkan. Semakin besar temperatur hidrolisis asam dan semakin lama waktu fermentasi yang dilakukan pada bahan akan menghasilkan kadar bioetanol yang semakin tinggi. 
Pada hidrolisis asam $60^{\circ} \mathrm{C}$ dengan waktu fermentasi 5, 7, dan 9 hari menghasilkan kadar bioetanol sebesar $22 \%, 41 \%$ dan $52 \%$. Sementara untuk hidrolisis asam $70^{\circ} \mathrm{C}$ dengan waktu fermentasi 5, 7, dan 9 hari menghasilkan kadar bioetanol sebesar $44 \%$, $48 \%$, dan $53 \%$. Dan pada hidrolisis asam $80^{\circ} \mathrm{C}$ dengan waktu fermentasi 5,7 , dan 9 hari menghasilkan kadar bioetanol sebesar $47 \%, 58 \%$, dan $56 \%$.

Namun pada hidrolisis asam $80^{\circ} \mathrm{C}$ dengan waktu fermentasi 9 hari mengalami penurunan kadar bioetanol yaitu $56 \%$ hal ini disebabkan karena batas dari fermentasi bahan tersebut hanya pada sampai temperatur $80^{\circ} \mathrm{C}$ dengan waktu fermentasi 7 hari, dengan kata lain ketika fermentasi melampaui batas fermentasi bahan maka kadar bioetanol akan mengalami penurunan.

\section{KESIMPULAN DAN SARAN}

\section{Kesimpulan}

Dari penelitian yang telah dilakukan maka dapat disimpulkan bahwa:

1. Temperatur hidrolisis asam berpengaruh terhadap kadar bioetanol. Kadar bioetanol yang paling tinggi adalah hidrolisis asam dengan suhu $80^{\circ} \mathrm{C}$ dengan kadar 58 $\%$ dan kadar bioetnol paling rendah terdapat pada hidrolisis asam dengan suhu $60^{\circ} \mathrm{C}$ dengan kadar $22 \%$.

2. Waktu fermentasi berpengaruh terhadap kadar bioetanol yang dihasilkan. Kadar bioetanol yang paling tinggi terdapat pada fermentasi 7 hari memperoleh kadar sebesar $58 \%$.

\section{Saran}

Perlu dilakukan pelenitian lanjutan menggunakan suhu diatas $80^{\circ} \mathrm{C}$ untuk mengetahui kadar bioetanol yang dihasilkan dan penyulingan secara dua tahap untuk menghasilkan kadar bioetanol yang lebih tinggi sehingga benar-benar dapat dijadikan bahan bakar alternatif.

\section{REFERENSI}

[1]. Arahim, Zaipudin. 2013. Ilmu Pengetahuan Alam. Klaten : CV. Grafika dua tujuh

[2]. Juwita, R. (2012). Studi Produksi Alkohol dari Tetes Tebu (Saccharum officinarum L) Selama Proses Fermentasi. Skripsi, Jurusan Teknologi Pertanian, Fakultas Pertanian, Universitas Hasanuddin, Makassar.

[3]. Tri Retno, D., \& Nuri, W. (2011, February). Pembuatan bioetanol dari kulit pisang. In Prosiding Seminar Nasional Teknik Kimia "Kejuangan" 2011

[4]. Purba, E. S. (2013). Pengaruh lama fermentasi terhadap kadar bioetanol dari biji alpukat (persea americana mill) (Doctoral dissertation, Fakultas Matematika dan Ilmu Pengetahuan Alam).

[5]. Asngad, A., \& Suparti, S. (2009). Lama Fermentasi Dan Dosis Ragi Yang Berbeda Pada Fermentasi Gaplek Ketela Pohon (Manihot Utilissima, Pohl) Varietas Mukibat Terhadap Kadar Glukosa Dan Bioetanol. Sains dan Teknologi, 10(1), 1-9.

[6]. Utami, Rina Sari, Eva pamungkas Sari,dan Inayati. 2014. Pengaruh Waktu Hidrolisa dan Konsentrasi Asam Pada Hidrolisa Pati Kentang Dengan Kualitas Asam.Universitas 11 Maret Vol.13 No.2 Hal. 45-49.

[7]. Purwadi, R. (2006). Continuous ethanol production from diluteacid hydrolyzates: detoxification and fermentation strategy (Doctoral dissertation, Göteborg: Chalmers tekniska 
högskola).

[8]. Suharto. 2017. Bioteknologi Dalam

Bahan Bakar Nonfosil.

Yogyakarta : ANDI 